\title{
A Prospective Observational Study to Know the Incidence of Placenta Previa and Comparing its Effect on Fetomaternal Outcome in Scarred and Unscarred Uterus at A Tertiary Care Centre
}

\section{Dr. Surendra ${ }^{1 *}$, Dr. Santosh Khajotia ${ }^{2}$}

${ }^{1}$ III Year Post Graduate Resident Doctor, Department of Obstetrics \& Gynecology, S.P. Medical College, PBM Hospital, Bikaner, Rajasthan 334001, India

${ }^{2}$ Senior Professor \& Unit Head, Department of Obstetrics \& Gynecology, S.P. Medical College, PBM Hospital, Bikaner, Rajasthan 334001, India

DOI: 10.36348/sijog.2020.v03i01.007 | Received: 21.01.2020 | Accepted: 28.01.2020 | Published: 30.01 .2020

*Corresponding author: Dr. Surendra

Abstract

Objective: To study the incidence of placenta previa. To examine the risk factors and fetomaternal outcomes in placenta previa in previously scarred and unscarred uterus in Dept. of Obstetrics \& Gynecology, S.P. Medical College, Bikaner. Methodology: The patients who came with complaint of painless bleeding per vagina after 28 weeks of gestation were hospitalized and were divided into two groups, Group A in which placenta previa occurred in a previously scarred uterus and Group B in which placenta previa occurred in an unscarred uterus. Results: The overall incidence of the placenta previa was $0.56 \%$. Incidence of placenta previa in group A (Scarred uterus) was $1.15 \%$ which was higher than group B (Unscarred uterus) i.e. $0.35 \%$. Cesarean section with Uterine artery ligation and uterine packing was present in $12.9 \%$ cases and $3.70 \%$ cases respectively in group A while in $2.08 \%$ cases each in group B. Previous 1 LSCS and previous 2 LSCS was present as a risk factor in group A only in $88.89 \%$ cases \& $11.11 \%$ cases respectively. Conclusion: An increase in incidence of prior cesarean section and advanced maternal age probably contributes to a rise in number of pregnancies complicated with placenta praevia and its association with adverse maternal \& perinatal outcome. Early diagnosis by ultrasound and planned delivery should be the mainstay of management.

Keywords: Placenta previa, incidence, PPH, complication, fetomaternal outcome.

Copyright @ 2020: This is an open-access article distributed under the terms of the Creative Commons Attribution license which permits unrestricted use, distribution, and reproduction in any medium for non-commercial use (NonCommercial, or CC-BY-NC) provided the original author and source are credited.

\section{INTRODUCTION}

Placenta, the life support system of fetus, when implants in lower uterine segment affects fetomaternal outcome adversely. Hemorrhage is leading cause of death worldwide. Placenta previa is a major cause of hemorrhage worldwide and frequency of this condition is on rise [1, 2]. Placenta Previa is an obstetric complication that occurs in the second and third trimester of pregnancy. It may cause serious morbidity and mortality to the mother. Placenta previa when diagnosed in 2 nd or 3 rd trimester is associated with series of complications [3].

Significant maternal morbidity in the form of increased incidence of fetal malpresentation, cesearean delivery, increased blood loss and peripartum hysterectomy have been noted in cases of placenta previa and can lead to prolonged hospitalization in these women [4]. Premature deliveries can occur which lead to higher admission to neonatal intensive care unit and stillbirths $[5,6]$.

The emphasis should be on institutional delivery in a tertiary care centre with multidisciplinary care i.e. involvement of senior obstetrician, neonatologist, sonologist, anaesthetist and hematologist. Early diagnosis by ultrasound and planned delivery should be the goal.

\section{AIMS AND OBJECTIVES}

To determine the incidence of placenta previa and to examine the risk factors and fetomaternal outcomes in placenta previa in previously scarred and unscarred uterus group in Department of Obstetrics \& Gynecology. 


\section{MATERIAL AND METHODS}

It was a prospective observational study conducted in Department of Obstetrics \& Gynecology, S. P. Medical College from $1^{\text {st }}$ October 2018 to $30^{\text {th }}$ September 2019. All the pregnant female who presented with complaint of painless bleeding per vagina after 28 weeks of gestation were hospitalized during the period of data collection i.e. 1st October 2018 to $30^{\text {th }}$ September 2019. Total no. of deliveries during the study period were 18,077, out of which 102 cases had placenta previa. These patients were divided into two groups, 54 patients in scarred uterus group \& 48 patients in unscarred uterus group.

Inclusion Criteria: Patients who give consent to participate in study and presented with complaint of painless bleeding per vagina after 28 weeks of gestation.

Exclusion Criteria: Patients not willing to participate in the study and patients with period of gestation less than 28 weeks. Patients with abruptio placentae and patients with bleeding due to local cervical causes.
All the required information was collected in pre- structured and pretested proforma to fulfill objectives of study. All subjects were asked for verbal and written consent before enrolling them in study. Gestational age was assessed by last menstrual period and confirmed by first trimester ultrasonography.

\section{DATA ANALYSIS}

Data was analysed using appropriate software (Microsoft Excel and SPSS). All the information collected was arranged in a master chart which was used to compare data and $\mathrm{p}$ value less than 0.05 was considered statistically significant. Chi square test and $t$ test was used to calculate the result.

\section{OBSERVATION AND RESULT}

The present study comprises of 102 patients. Cases were selected by taking into consideration all inclusion and exclusion criteria. In this study following observations were drawn.

Table-1: Incidence of Placenta previa

\begin{tabular}{|l|l|l|l|}
\hline & Group A Scarred uterus $(\mathbf{n}=\mathbf{5 4})$ & Group B Unscarred uterus $(\mathbf{n = 4 8})$ & Total \\
\hline No of cases with placenta previa & 54 & 48 & 102 \\
\hline Total delivery & 4706 & 13371 & 18077 \\
\hline Incidence & $\mathbf{1 . 1 5} \%$ & $\mathbf{0 . 3 5} \%$ & $0.56 \%$ \\
\hline
\end{tabular}

Incidence of placenta previa in group A (Scarred uterus) was $1.15 \%$ which was higher than the incidence in group B (Unscarred uterus) i.e. 0.35\%.The overall incidence of the placenta previa was $0.56 \%$.

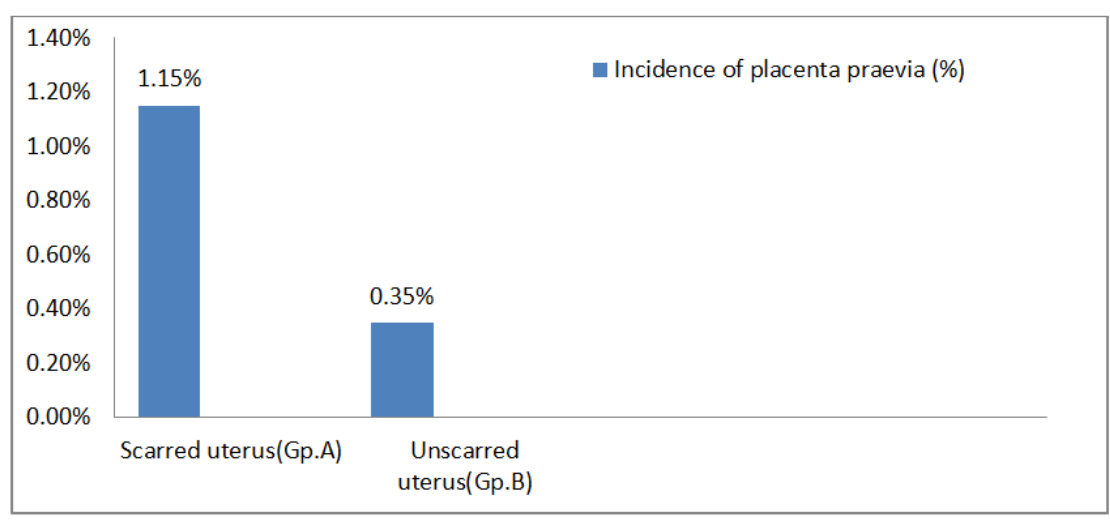

Graph-1: Incidence of Placenta previa

Table-2: Distribution of cases according to the Mode of delivery

\begin{tabular}{|l|l|l|l|l|l|}
\hline \multirow{2}{*}{ Mode of delivery } & \multicolumn{3}{|l|}{ Group A Scarred uterus $(\mathbf{n}=\mathbf{5 4})$} & Group B Unscarred uterus $(\mathbf{n}=\mathbf{4 8})$ & \multirow{2}{*}{ P value $\left(\mathbf{x}^{\mathbf{2}}\right.$ test $)$} \\
\cline { 2 - 5 } & No. of cases & Percent & No. of cases & Percent & \\
\hline Caesarean Section & 54 & $100.00 \%$ & 46 & $95.83 \%$ & $\mathbf{0 . 0 1 8}$ \\
\hline PTVD & 0 & $0.00 \%$ & 2 & $4.17 \%$ & \\
\hline TOTAL & $\mathbf{5 4}$ & $\mathbf{1 0 0 . 0 0 \%}$ & $\mathbf{4 8}$ & $\mathbf{1 0 0}$ & \\
\hline
\end{tabular}

All the cases in Group A i.e. 100.00\% and 46 cases of Group B i.e.95.83\% cases underwent cesarean section. Difference between both groups was found to be statistically significant $(\mathrm{P}=0.018)$. 
Surendra \& Santosh Khajotia; Sch Int J Obstet Gynec, Jan. 2020; 3(1): 22-26

Table-3: Distribution of cases based on the Fetal outcome

\begin{tabular}{|l|l|l|l|l|l|}
\hline \multirow{2}{*}{ Fetal outcome } & \multicolumn{2}{|l|}{ Group A Scarred uterus $(\mathbf{n}=\mathbf{5 4})$} & Group B Unscarred uterus $(\mathbf{n}=\mathbf{4 8})$ & \multirow{2}{*}{ P value $\left(\mathbf{x}^{2}\right.$ test $)$} \\
\cline { 2 - 5 } & No. of cases & Percent & No. of cases & Percent & \\
\hline Alive & 44 & $81.48 \%$ & 34 & $70.83 \%$ & 0.155 \\
\hline Still Birth & 8 & $14.81 \%$ & 6 & $12.50 \%$ & 0.959 \\
\hline Neonatal death & 2 & $3.70 \%$ & 8 & $16.67 \%$ & 0.062 \\
\hline TOTAL & $\mathbf{5 4}$ & $\mathbf{1 0 0 . 0 0 \%}$ & $\mathbf{4 8}$ & $\mathbf{1 0 0 . 0 0 \%}$ & \\
\hline
\end{tabular}

No. of live neonates in Group A were found in $81.48 \%$ cases while it was $70.83 \%$ cases in Group B \&the difference between the two groups was not to be found statistically significant.

Table-4: Distribution of cases based on the related complications

\begin{tabular}{|l|l|l|l|l|l|}
\hline \multirow{2}{*}{ Related complications } & \multicolumn{2}{|l|}{ Group A Scarred uterus $(\mathbf{n}=\mathbf{5 4})$} & \multicolumn{2}{l|}{ Group B Unscarred uterus $(\mathbf{n}=48)$} & \multirow{2}{*}{ P Value $\left(\mathbf{x}^{2}\right.$ test) } \\
\cline { 2 - 5 } & No. of cases & Percent & No. of cases & Percent & \\
\hline PPH & 8 & $14.81 \%$ & 2 & $4.17 \%$ & 0.141 \\
\hline Fetal malpresentation & 8 & $14.81 \%$ & 5 & $10.42 \%$ & 0.713 \\
\hline Placenta accreta & 2 & $3.70 \%$ & 0 & $0.00 \%$ & - \\
\hline Placenta percreta & 1 & $1.85 \%$ & 0 & $0.00 \%$ & - \\
\hline Haemorrhagic shock & 0 & $\mathrm{O} \%$ & 1 & $2.08 \%$ & - \\
\hline Preterm birth & 50 & $92.59 \%$ & 42 & $87.5 \%$ & 0.596 \\
\hline
\end{tabular}

Preterm birth was the major complication in both the groups i.e. group A $92.59 \%$ cases and in group B $87.5 \%$ cases and this difference between both the groups was not to be found statistically significant $(\mathrm{P}=0.596)$.

Table-5: Distribution of cases based on the management of complications of placenta previa

\begin{tabular}{|l|l|l|l|l|l|}
\hline \multirow{2}{*}{$\begin{array}{l}\text { Management of Related } \\
\text { complications }\end{array}$} & \multicolumn{2}{|l|}{$\begin{array}{l}\text { Group A Scarred uterus } \\
(\mathbf{n = 5 4 )}\end{array}$} & \multicolumn{2}{l}{$\begin{array}{l}\text { Group B Unscarred uterus } \\
(\mathbf{n = 4 8})\end{array}$} & $\begin{array}{l}\text { P Value } \\
\left(\mathbf{x}^{2} \text { test }\right)\end{array}$ \\
\cline { 2 - 6 } & No. of cases & Percent & No. of cases & Percent & \\
\hline CS with Uterine artery ligation & 7 & $12.96 \%$ & 1 & $2.08 \%$ & 0.095 \\
\hline CS with placental bed suturing & 11 & $20.37 \%$ & 0 & $0 \%$ & - \\
\hline Uterine packing & 2 & $3.70 \%$ & 1 & $2.08 \%$ & 0.917 \\
\hline C. Hysterectomy & 5 & $9.26 \%$ & 0 & $0 \%$ & - \\
\hline
\end{tabular}

Cesarean section with Uterine artery ligation and uterine packing was present in $12.9 \%$ cases and $3.70 \%$ cases respectively in group A while in $2.08 \%$ cases each in group B and this difference was not to be found statistically significant $(\mathrm{P}=0.095$ in Cesarean section with uterine artery ligation and $\mathrm{P}=0.917$ in uterine packing cases).

Table-6: Distribution of cases based on the risk factors associated with placenta previa

\begin{tabular}{|l|l|l|l|l|l|}
\hline \multirow{2}{*}{ Risk factors } & Group A Scarred uterus & \multicolumn{2}{l|}{ Group B Unscarred uterus } & \multirow{2}{*}{ P Value $\left(\mathbf{x}^{2}\right.$ test $)$} \\
\cline { 2 - 5 } & No. of cases & Percent & No. of cases & Percent & \\
\hline Previous 1 LSCS & 48 & $88.89 \%$ & 0 & $0.00 \%$ & - \\
\hline Previous 2 LSCS & 6 & $11.11 \%$ & 0 & $0.00 \%$ & - \\
\hline Dilation \& Curettage & 8 & $9.26 \%$ & 6 & $6.25 \%$ & 0.959 \\
\hline Multigravida & 1 & $1.85 \%$ & 2 & $4.17 \%$ & 0.917 \\
\hline Anaemia & 10 & $18.52 \%$ & 11 & $22.92 \%$ & 0.762 \\
\hline PIH & 4 & $7.41 \%$ & 3 & $6.25 \%$ & 0.872 \\
\hline Elderly Multipara & 0 & $0.00 \%$ & 12 & $25.00 \%$ & - \\
\hline Elderly Primipara & 0 & $0.00 \%$ & 2 & $4.17 \%$ & - \\
\hline Young Primipara & 0 & $0.00 \%$ & 1 & $2.08 \%$ & - \\
\hline H/o of MRP & 0 & $0.00 \%$ & 1 & $2.08 \%$ & - \\
\hline Twin (IVF) & 0 & $0.00 \%$ & 1 & $2.08 \%$ & - \\
\hline Idiopathic & 0 & $0.00 \%$ & 17 & $35.41 \%$ & - \\
\hline
\end{tabular}

Previous 1 LSCS and previous 2 LSCS was present as a risk factor in group A only in $88.89 \%$ cases $\& 11.11 \%$ cases respectively. Anaemia was present in
$18.52 \%$ cases in group A and in $22.92 \%$ cases in group B. PIH accounted for $7.41 \%$ cases in group A and $6.25 \%$ cases in group B. 


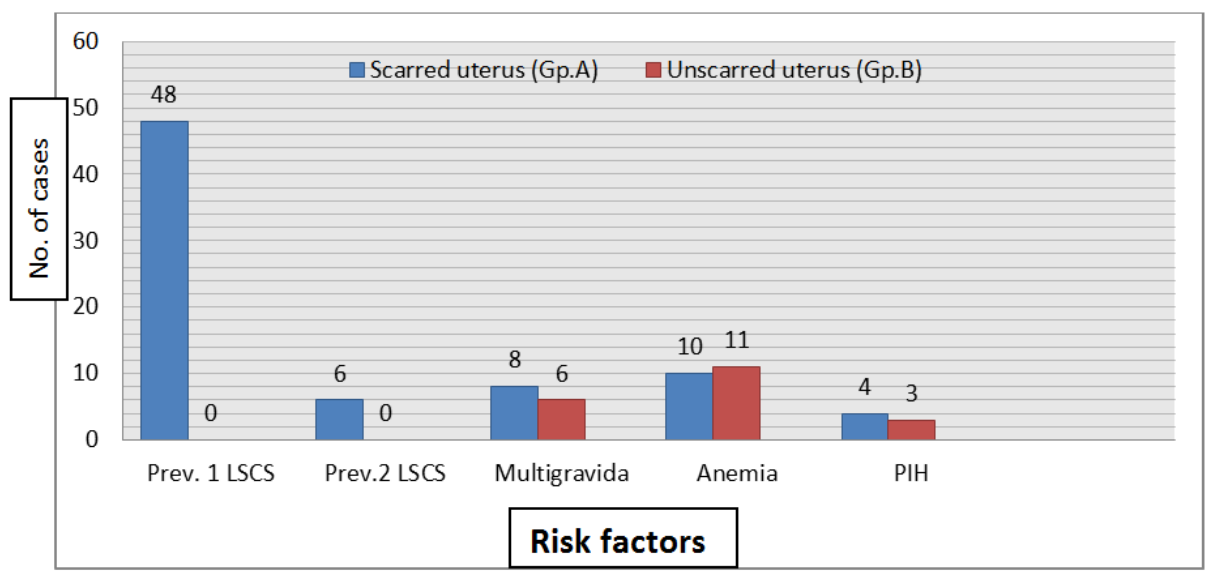

Graph-2: Distribution of cases based on the risk factors associated with placenta previa

\section{DISCUSSION}

The incidence of this situation is on rise so we need to identify women with high risk factors during antepartum period for early diagnosis and prompt management to reduce maternal and fetal morbidity and mortality. Incidence of placenta previa in group A (scarred uterus) was $1.15 \%$ which was much higher than in group B (unscarred uterus) i.e. $0.35 \%$ in present study, similar to many studies. For example Purvi Parikh et al., [10], the incidence was $1.14 \%$ in scarred uterus and $0.49 \%$ in unscarred uterus whose results are comparable with our study.

All the cases in Group A and $95.83 \%$ cases in Group B underwent cesarean section as a mode of delivery. Difference between both groups was found to be statistically significant $(\mathrm{P}=0.018)$. In a study conducted by Sarojini et al., [11] where 91 cases $(85.8 \%)$ were delivered by cesarean section and 15 cases $(14.2 \%)$ were delivered by vaginal route. The mode of delivery is determined by clinical state of the mother, fetus, and ultrasound findings. In minor degrees of placenta previa vaginal delivery is possible.

PPH was in less proportion when compared with a study conducted by Kavitha et al., [8] (June 2011 to May 2016) where it was found in $44.4 \%$ cases in scarred uterus group and $34.1 \%$ cases in unscarred uterus group. This is probably due to timely intervention performed due to team work and efficient care pathway. Malpresentation are common in placenta previa i.e. $14.81 \%$ in scarred group where as $10.42 \%$ in unscarred uterus and results are comparable with a study conducted by Mathuriya et al., [7] in which malpresentation was found in $11 \%$ cases in scarred uterus group and $8.4 \%$ cases in unscarred uterus group. Rajshree Dayanand Katke [12] found placenta accreta in $6.7 \%$ cases in scarred uterus group and none in unscarred uterus group.
Cesarean section with uterine artery ligation and uterine packing was present more in group $\mathrm{A}$ i.e. $12.9 \%$ cases and $3.70 \%$ cases respectively than $2.08 \%$ cases each in Group B, \& this difference was not to be found statistically significant $(\mathrm{P}=0.095$ and $\mathrm{P}=0.917$ respectively). Mathuriya et al., [7] found uterine artery ligation in $20 \%$ cases in scarred uterus group and $5.6 \%$ cases in unscarred uterus group. In our study hysterectomy was found only in scarred uterus (Group A) in $9.26 \%$ cases and none in unscarred uterus (Group B). This is supported by a study conducted by Mathuriya et al., [7] where hysterectomy was found in $8 \%$ cases in scarred uterus group.

Previous LSCS was present as a risk factor in group A only. While elderly multipara i.e. $25 \%$ cases, elderly primipara i.e. $4.17 \%$ cases, young primipara i.e. $2.08 \%$ cases, twin (IVF) i.e. $2.08 \%$ cases and idiopathic risk factors i.e. $10.42 \%$ cases were present in group B only. D \& C, Multigravida, Anemia, PIH are risk factors present in both the groups \& this difference was not to be found statistically significant. Kavitha et al., [8] found severe anemia in $19.4 \%$ cases in scarred uterus group and $11.4 \%$ cases in unscarred uterus group

Placenta previa is one of the most dreaded complications in obstetrics due to its associated adverse maternal and perinatal outcome. The frequency of cesarean section is increasing worldwide with a parallel rise in maternal mortality and morbidity [9]. This study confirms that risk of placenta previa increases with prior cesarean deliveries and chances of previa increases in scarred uterus in succeeding pregnancies as compared to unscarred uterus so every effort must be done to decrease the number of cesarean deliveries in the first place.

Sonographic detection of anterior placenta and doppler ultrasound should be carried out to rule out placenta accreta so that the obstetricians can be aware of the massive maternal hemorrhage and to reduce the morbidity associated with placenta previa. 


\section{CONCLUSION}

Our study concludes that all efforts should be made to reduce the rate of operative deliveries like careful evaluation of indication of cesarean section, ethical clinical practice and counselling of woman for prevention through family planning.

\section{KEY NOTE}

Primary prevention in the form of reduction in the rate of primi cesearean section must be done in order to prevent likelihood of placenta previa in scarred uteri. The emphasis should be on institutional delivery in a tertiary care centre with multidisciplinary care will improve the fetomaternal outcome.

\section{REFERENCES}

1. Cunningham, F., \& Williams J. W. (2018). Illiamsobstetrícs 25th Ed. México, McGraw-Hill Education; 801.

2. Meena, N., Dave, A., Meena, S., Meena, A., \& Shrivastava, A. (2015). Impact of placenta praevia on obstetric outcome. Int $J$ Reprod Contracept Obstet Gynecol, 4(1), 76-80.

3. Neale, E. J., \& Rogers, M. S. (1989). Vaginal ultrasound for ruling out placenta praevia. Case report. BJOG: An International Journal of Obstetrics \& Gynaecology, 96(7), 881.

4. Oppenheimer, L. (2007). Society of obstetricians and Ggnaecologists of Canada. Diagnosis and management of placenta praevia.J Obstet Gynaecol Can, 29(3), 261-73.

5. Hung, T. H., Hsieh, C. C., Hsu, J. J., Chiu, T. H., Lo, L. M., \& Hsieh, T. S. T. A. (2007). Risk factors for placenta previa in an Asian population. International Journal of Gynecology \& Obstetrics, 97(1), 26-30.

6. ACOG committee on Obstetric Practice. (2002). ACOG committee opinion. Number 266, Jan 2002: Placenta Accreta. Obstet Gynecol, 99:169170.

7. Mathuriya, G., \& Lokhande, P. (2013). Comparative Study of Obstetrics Outcome Between Scarred and Unscarred Uterus in Placenta Previa Cases. Indian Journal Clin Pract, 24.

8. Kavitha, B., \& Hota, B. M. (2018). Clinical study of placenta previa in scarred and unscarred uterus. Journal of Dr. NTR University of Health Sciences, 7(1), 13-18.

9. Mazumder, U., Rouf, S., \& Sarkar, S. (2017). Placenta Previa With History of Previous Caesarean Delivery-An Obstetrician's Nightmare. Journal of Woman's Reproductive Health, 1(4), 33-38.

10. Parikh, P. M., Makwana, S., Shah, S., \& Vithalani, V. (2016). Feto-Maternal Outcome in Placenta Previa in Scarred Uterus Vs Non Scarred Uterus. IOSR Journal of Dental and Medical Sciences (IOSR-JDMS), 15(1):69-73.

11. Sarojini, M. K., \& Bhanu, A. B. (2016). Radhika. Clinical study of placenta previa and its effect on maternal health and fetal outcome. Int J Reprod Contracept Obstet Gynecol, 5, 3496-3499.

12. Katke, R. D. (2016). Placenta previa: Outcomes in scarred and unscarred uterus. International Journal Reprod Contracept Obstet Gynecol, 5(8), 2728-2732. 